\title{
CORREDOR DE EXPORTAÇÃO NORTE E A VIABILIDADE PELA LOGÍSTICA DE TRANSPORTE
}

\author{
PEREIRA, Vanessa Lopes Galdiano \\ ROCHA, Viviane Pereira de Souza \\ BONACIM, Carlos Alberto Grespan
}

Recebido em: 2008-08-14

Aprovado em: 2008-09-19

ISSUE DOI: $10.3738 / 1982.2278 .134$

RESUMO: O trabalho tem como objetivo demonstrar a percepção dos produtores rurais a cerca da viabilidade logística de transportes do Corredor de Exportação Norte, que abrange os estados do Sudeste do Piauí, Sul do Maranhão e Norte e Sudeste do Tocantins. A parte empírica do trabalho trata de uma investigação tendo como metodologia o estudo de caso. Em síntese, têm-se o seguinte para decisão de plantio no sul do Maranhão, primeiro pelo critério de logística de escoamento de grãos, uns dos melhores do Brasil, com a facilidade no transporte de grãos através do sistema rodoviário, ferroviário e marítimo, segundo pela topografia da região e tipo de solo propício ao desenvolvimento agrário, e terceiro pelo baixo custo na aquisição de terra de cerrados. $\mathrm{O}$ estudo demonstra que o transporte movimentado pelo Corredor está se tornando eficiente com relação a outras regiões tradicionais do país, proporcionado maior competitividade para exportação.

Palavras-chave: Custos. Transporte. Logística. Corredor Norte.

SUMMARY: The work aims to demonstrate the perception of rural producers about the viability of transport logistics corridor Export North, which covers the states of Piauíi southeastern, southern and northern Maranhão and Tocantins southeast .. The empirical part of the work it is an empirical research methodology using as case study. In summary have been the following decision for planting in the south of Maranhão, the first criterion for the logistics of marketing of grain, some of the best of Brazil, with the ease in the transport of grain through the system road, rail and sea, the second by topography of the region and soil type favorable to agricultural development and the third by the low cost of the acquisition of land from closed. The study shows that the transport corridor is busy by becoming efficient relative to other traditional regions of the country, providing greater competitiveness for export.

Keywords: Costs. Transport. Logistics. North Corridor.

\section{INTRODUÇÃO}

Os fretes agroindustriais têm peso significativo no custo do agronegócio, e sua mensuração se dá por meio de procedimentos matemáticos que representam uma estimativa de valor. Os insumos, como adubos, fosfatos e sulfatos, necessários para produção agrícola, também são importados de outros países e transportados por marítimas, chegando nas 
fazendas a um custo (frete). Já o escoamento da produção exige uma estrutura de logística, incorrendo em custos de transporte.

O Brasil, com sua grande extensão territorial e com a maior quantidade de terras agricultáveis do mundo, só vai viabilizar a produção agrícola com uma política para desenvolvimento do transporte, tendo a ferrovia como prioridade, pois é o transporte ideal para produtos agrícolas, são grandes volumes de carga com destino certo e grande distâncias. Por conta do modelo de privatização em boa parte das ferrovias brasileiras, diversas distorções apareceram e ainda não foram corrigidas.

As empresas operadoras da malha ferroviária nacional não podem simplesmente escolher o caminho mais curto para o seu destino. Várias empresas foram criadas, cada uma com sua respectiva área de domínio. Quando da necessidade de passar por uma linha que não seja de sua propriedade, é necessário pagar o chamado "direito de passagem", espécie de pedágio que encarece o preço do frete. Isso faz com que nem sempre o caminho mais curto seja o mais barato, o que diminui a eficiência do setor.

O corredor norte de exportação possui vários itens necessários para uma melhor logística de recebimento de insumos e distribuição de grãos produzidos na região: (i) potência de produção - o sul do Maranhão e Piau, norte do Tocantins, têm 4.925.000 ha de cerrado, ideal para agricultura e próprio para o cultivo de soja, milho e outros cereais; (ii) encontra-se, também na região, uma moderna ferrovia administrada pela Vale do Rio Doce, que liga Carajás à ao Porto de Itaquí, em São Luís/MA, ligando à ferrovia Norte Sul, com trecho construído ate a cidade Porto Franco, onde existe um terminal intermodal (local onde os caminhões descarregam a carga para a ferrovia), ligando a ferrovia com a rodovia Belém Brasília e hidrovia pelo Rio Tocantins e Araguaia (ainda em construção).

A soja produzida na região é transportada pela ferrovia, vai até São Luís, e de lá segue por navios até o mercado consumidor, com a vantagem de São Luís estar 4000 km mais perto de Roterdã, na Europa, do que o porto de Paranaguá/PR, porto de maior movimentação agrícola do país.

Pretende-se descrever a problemática da atual situação das estradas brasileiras, colocando como ponto forte à ferrovia suas facilidades e benefícios, e também mostrando que com as cargas direcionadas às ferrovias, as estradas se livram dos caminhões e melhora a infra-estrutura para os veículos de passeio, evitando os congestionamentos.

Sem registrar incremento há mais de 20 anos, o complexo logístico brasileiro está 
perto de um caos, o que coloca em xeque o crescimento do agronegócio. Os custos decorrentes das más condições de transporte de grãos trazem prejuízos aos produtores e ao país, que deixa de ganhar importantes quantias por conta da inoperância da logística nacional.

De acordo com Grupo de Estudos de Integração de Política de Transportes -GEIPOT (2004), o Brasil tem um gasto adicional de R 132 milhões ao ano com o transporte de soja devido a má distribuição modal, cujas rodovias são responsáveis por transporte de $80 \%$ do total produzido, sendo que a distribuição ideal seria de $40 \%$ para rodovias, $33 \%$ para as ferrovias e $27 \%$ para as hidrovias.

Segundo a CNT (2004), o estado de conservação de 82\% das estradas brasileiras está qualificado entre péssimo e ruim. Seriam necessários aproximadamente oito bilhões de reais e dois anos de obras para reconstrução e manutenção das atuais rodovias, para que só então começassem novos investimentos.

O trabalho tem como objetivo demonstrar a percepção dos produtores rurais acerca da viabilidade logística de transportes do Corredor de Exportação Norte, que abrange os estados do Sudeste do Piauí, Sul do Maranhão e Norte e Sudeste do Tocantins.

A parte empírica do trabalho terá o objetivo de ajudar a responder ao problema de pesquisa por meio da análise do contexto da região. Trata-se de uma investigação que usa como metodologia o estudo de caso.

De acordo com Yin (2005), o estudo de caso é uma pesquisa empírica que investiga um fenômeno contemporâneo dentro de um contexto real, quando os limites entre fenômeno e contexto não são claramente definidos e nas quais múltiplas fontes de evidências são usadas.

Martins (2006) define estudo de caso como uma estratégia de pesquisa caracterizada pela análise profunda e intensa de uma unidade social que pede avaliação qualitativa.

\section{COMO FUNCIONA O TRANSPORTE FERROVIÁRIO, RODOVIÁRIO E AS HIDROVIAS}

O transporte ferroviário em qualquer parte do mundo, sempre foi o mais econômico para transporte de grandes volumes de cargas num trecho com destino certo, em relação ao transporte rodoviário.

Embora o custo de implantação de uma ferrovia gira em torno de 07 a 10 vezes mais caro que a construção de uma rodovia, uma vez que para os trajetos ferroviários são necessárias grandes obras de construções civis, ferrovias não permitem muitas inclinações e necessitam de pontes e viadutos reforçados devido às vibrações dos comboios. 
Mas, em contrapartida, ganha na manutenção e na durabilidade, também no custo final do transporte e principalmente no volume de carga, sem interferência de trânsitos ou condições climáticas, favorecendo o just in time, ou seja, o tempo certo combinado de carga, transporte e descarga, o que é muito importante nos tempos de hoje, onde os contratos de vendas são atrelados ao prazo de entrega, pesando grandes multas pelo não comprimento.

Esta é a grande diferença entre os dois meios de transporte, muito embora as cargas necessitem sempre das rodovias para chegar até aos terminais ferroviários.

Temos no país uma cultura voltada para as rodovias, mais pelo custo de implantação do que por decisão técnica, num país de poucos recursos como o Brasil, sempre decidem pelo mais rápido e mais barato, optando pelas rodovias.

Mas novas idéias vêm surgindo. Em 2003 foi criado o projeto de Lei n.2546/03, onde foram criadas as condições básicas para a implantação dos PPPs, ou seja, Programa de Parcerias Público Privadas, que em síntese procura viabilizar e atrair recursos privados para investimentos em infra-estrutura no país. O projeto é uma resposta à carência de recursos públicos para investimentos nestas áreas.

Um dos primeiros projetos neste sentido foi realizado numa rodovia no Mato Grosso, construindo um trecho de $61 \mathrm{~km}$ ligando a cidade de Tapurah e Lucas do Rio Verde, através de uma parceria entre produtores rurais, prefeitura e governo do estado.

O governo tem vários outros projetos de PPPs em andamento e uma das prioridade do governo Lula é da construção de mais um trecho da Ferrovia Norte Sul, ligando a cidade de Estreito/Ma até Gurupi/To, numa distância de mais de 600 km, mudando o cenário agrícola de uma das regiões com o maior potencial agrícola do país.

O Brasil possui 42.000 quilômetros de hidrovias, dos quais apenas 25.000 são navegáveis, sendo 15.000 durante todo o ano. Desse total, 7.000 quilômetros encontram-se na região amazônica e o resto espalhado por todo território nacional. Em se tratando de transporte na água, as hidrovias ficam com 5\% do transporte, enquanto, o transporte marítimo acumula $95 \%$.

Nos Estados Unidos, por exemplo, 52\% de suas águas são navegáveis. Para SOARES (2004), fazer uma hidrovia mais forte é uma questão de vontade política e não tem outra solução senão o governo bancar os investimentos necessários.

Se comparados a outros modais, como a ferrovia e a rodovia, a hidrovia ainda "engatinha”, apenas da má situação dos outros sistemas. Segundo especialistas, não há no país uma política hidroviária sólida capaz de colocar esse meio de transporte como uma solução 
viável para regiões de boa navegação.

Apesar de o país possuir ao todo 47 portos contanto marítimos e fluviais, suas instalações são precárias e não há ligação satisfatória com outros modais. A falta de silos para armazenagem de grãos é outro grande entrave. Como o Brasil possui capacidade instalada para armazenar cerca de $60 \%$ de sua produção, caminhões, trens e embarcações acabam tornando-se silos móveis, que guardam a produção nacional, enquanto esta não chega nas indústrias ou nos portos para ser exportada.

Uma das maiores empresas de agronegócio e a terceira maior exportadora do país, a "Bunge Fertilizantes", realizou recentemente um levantamento dos custos gerados pela ineficiência da infra-estrutura logística. Os resultados chamam a atenção, pois as perdas previstas para safra 2005/2006 atingem US\$ 2,5 bilhões. Metade disso fica entre a lavoura e o porto, em caminhos longos, estradas deterioradas, armazenagem deficiente e outros problemas.

A outra metade se perde em longos atrasos a beira do cais, a espera do navio partir. Segundo Adalgiso Telles, diretor corporativo da empresa, a conta vai parar nos bolsos de todos os envolvidos, o que reduz a margem de lucro de toda a cadeia produtiva. Um exemplo prático é a diferença no resultado final da soja - a brasileira gera um ganho inferior a US\$ 16/t quando comparado aos da concorrente, sendo US\$ 3,00 única e exclusivamente em custos portuários.

Além do problema de custo dos portos, existe risco de perder compradores devido à demora nas entregas.

\section{O QUE É LOGÍSTICA}

Em estudo realizado pelo GEIPOT (2004), foram analisados 16 pólos de produção de soja, englobando a região Centro-Oeste, o sul da região Norte e o oeste da região Nordeste. Rotas otimizadas, por todo o território foram traçadas, o que atenderia por completo as necessidades logísticas nacionais.

De acordo com a projeção, no final da implantação do programa, em 2015, o país economizaria $\mathrm{R} \$ 382$ milhões em frete, o que tornaria os produtos agrícolas brasileiros ainda mais competitivos. São os caminhos de menor custo até os portos de exportação, através dos quais a soja brasileira chega mais competitiva ao exterior.

Para Ballou (1996), a logística empresarial associa estudo e administração dos fluxos de bens e serviços e da informação associada que os põe em movimento. Vencer tempo e 
distância na movimentação de bens ou na entrega de serviços de forma eficaz e eficiente é a tarefa do profissional de logística. Sua missão é colocar as mercadorias ou serviços certos no lugar certo e no instante corretos e na condição desejada, ao menor custo possível.

A logística empresarial trata de todas as atividades de movimentação e armazenagem, que facilitam o fluxo de produtos desde o ponto de aquisição da matéria-prima até o ponto de consumo final, assim como os fluxos de informação que colocam os produtos em movimento, com o propósito de providenciar níveis de serviço adequados aos clientes a um custo razoável.

A logística compõe-se de dois subsistemas de atividades: administração de materiais e distribuição física, cada qual envolvendo o controle da movimentação e a coordenação demanda-suprimento (DIAS, 1993).

A logística é o processo de gerenciar estrategicamente a aquisição, movimentação e armazenagem de materiais, peças e produtos acabados (e os fluxos de informações correlatas) através da organização e seus canais de marketing, de modo a poder maximizar a lucratividade presente e futura através dos pedidos a baixo custo (PAGOTTO, PIROLA e SILVA, 2000).

Diversos autores discorrem sobre logística de formas explicativas e complementares:

A logística consiste em uma técnica e, ao mesmo tempo, uma ciência que suporta a realização dos objetivos empresariais, a programação dos mesmos e consecução, serve para management, o engineering e as atividades técnicas nos temas solicitados, o projeto, o fornecimento e a preservação dos recursos (PAGOTTO; PIROLA; SILVA, 2000).

Percebe-se que o conceito de logística vai além da distribuição física, tratando não somente de itens materiais, mas também das informações relacionados em todas as fases do processo aquisição de bens e entrega ao consumidor final.

Ballou (1996) cita as atividades de transportes, manutenção de estoques e processamento de pedidos como sendo atividades primárias para que a logística atinja seus objetivos. O transporte é a atividade logística mais importante, porque ela absorve em média de um a dois terços dos custos.

Transporte refere-se aos vários métodos para se movimentar produtos, como rodoviário, ferroviário e aeroviário. Manutenção de estoques: nem sempre é possível produzir e entregar imediatamente ao cliente. Para se atingir um grau razoável de disponibilidade de produto é necessário manter estoque, que agem como "amortecedores" entre a oferta e a demanda. O custo dos estoques tem peso significativo no total dos custos logísticos. 
Enquanto o transporte adiciona valor de lugar ao produto o estoque adiciona valor de tempo. Processamento de pedidos: é a atividade primária que inicializa a movimentação de produtos e a entrega de serviços. Sua importância deriva do fato de ser um elemento critico em termos de tempo.

Ballou (1996) cita ainda que além das atividades primárias existem as atividades de apoio no sistema logístico, como: armazenagem, manuseio de materiais, embalagem de proteção, obtenção, programação de produtos e manutenção de informação. A armazenagem refere-se à administração do espaço necessário para manter estoques.

Envolve problemas como localização, dimensionamento de área, arranjo físico, projeto de docas ou baias e configuração do armazém. Manuseio de materiais: diz respeito à movimentação do produto no local de armazenagem, sendo necessário selecionar o equipamento de movimentação, procedimento para formação de pedidos. Embalagem de proteção: está relacionado ao bom projeto de embalagem do produto, que auxilia a garantir movimentação sem quebras.

Por sua vez, Maher (2001, p. 45) define cadeia de valor como "um conjunto interligado de atividades que aumenta a utilidade - o valor - dos produtos e serviços de uma organização". A cadeia de valor, portanto, diz respeito aos processos de agregação de valor ao(s) produtos(s) no ambiente interno da organização, como por exemplo, nas atividade de pesquisa e desenvolvimento, no desenho do produto, nos processos de distribuição e no serviço prestado ao cliente, no pós-venda. Cada uma dessas atividades traz uma contribuição ao processo de agregação de valor ao produto.

\section{CUSTOS LOGÍSTICOS}

Os custos representam parte importante na administração logística. Segundo (Dias, 1993 ) existe crescente interesse pela administração logística no Brasil, podendo ser explicado por seis razões principais:

1- Rápido crescimento dos custos, principalmente relativos aos serviços de transporte e armazenagem; 2- Desenvolvimento de técnicas matemáticas e do equipamento de computação capazes de tratar eficientemente a massa de dados normalmente necessária para a análise de um problema logístico; 3- Complexidade crescente da administração de materiais e da distribuição física, tornando necessários sistemas mais complexos; 4- Disponibilidade de maior gama de serviços logísticos; 5- Mudanças de mercado e de canais de distribuição, 
especialmente bens de consumo; 6- Tendência de os varejistas e atacadistas transferirem as responsabilidades de administração dos estoques para os fabricantes.

O custo total logístico depende dos custos básicos de transporte e de manutenção de estoque, das características do produto, localização, fontes de suprimento e mercado. Conforme Dias (1993), cada elemento adiciona custos ao produto final e influencia as decisões tomadas por outros membros, resultando alguns conflitos, visto que cada elemento individual pretende minimizar seus próprios custos e reduzir riscos, como: (i) os fornecedores desejam produzir grandes lotes de produtos comuns a diversos clientes; (ii) o produtor deseja fabricar grandes lotes de um conjunto de produtos com projeto simples e facilidade de montagem, tendo ainda garantia de qualidade de cada produto individual; (iii) o revendedor deseja qualidade superior e um bom desempenho comercial associado à marca conhecida, com um preço de garantia alta margem de lucro; e (iv) o consumidor, por sua vez, deseja qualidade superior, desenho individual, preço baixo e boa marca.

\section{PESQUISA DE CAMPO - APLICAÇÃO PRÁTICA DO ESTUDO}

Realizamos uma pesquisa com seis produtores de grãos residentes e domiciliados no estado de São Paulo especificamente na cidade de Ituverava-SP, que optaram por plantar no Sul do Maranhão. Esses produtores a um questionário de 12 questões que nos ajudou a chegar a algumas conclusões.

O Questionário procurou identificar as vantagens e desvantagens de se investir no estado do Maranhão, viabilizando custos e logística de transporte e também o escoamento da produção de grãos através do Corredor de Exportação Norte.

Por meio da aplicação do questionário, foi possível identificar as vantagens e desvantagens de se plantar no Maranhão, visando mostrar toda logística de escoamento de grãos e também as vantagens em relação ao custo do transporte e a facilidade de chegar até o mercado externo.

Com o estudo da aplicação dos questionários verifica-se que:

1. Os principais fatores da escolha do local foram critérios técnicos de manejo, logístico e mercadológico, abrangendo topografia plana, preço p/há, compatível com a expansão do local e logística de escoamento dos grãos para exportação via porto e pluviometria regular.

2. Por meio de rodovias, ferrovias e porto marítimo e distancia do mercado consumidor.

3. As vantagens são: tipo de solo, topografia ideal, logística de escoamento da produção, custo

Nucleus, v.5, n.2, out. 2008 
de aquisição das terras e custo do transporte mais viável; desvantagens: pouca infra-estrutura, como exemplo falta de energia elétrica, assistência técnica, falta de incentivo do governo e péssimas estradas.

4. Por meio de um levantamento de dados quanto ao clima, produção e logística do local, fornecidos por uma cooperativa e entidades como Embrapa.

5. O planejamento foi feito por técnicos, por cooperativas fazendo todo um levantamento quanto à viabilidade do empreendimento e retorno do capital investido.

6. O preço por hectare (ha), custo do transporte e logística mercadológica são os melhores benefícios oferecidos pela região.

7. A região não goza de assistência técnica oferecida por cooperativas.

8. Como todos os estados o governo não incentiva os produtores de grãos quanto à exportação.

9. O custo da região do maranhão é um dos melhores do Brasil, considerando a soja quando chega ao porto e este esta mais próximo da Europa ou Ásia.

10. O custo de produção é muito parecido com a região sudeste, ganhando pela topografia plana e o menor custo hora/máquina/ha.

11. Em termos logísticos, o que deixa a desejar é a má qualidade das estradas.

12. A exportação é um dos parâmetros que fizeram os produtores a optarem pela região do Maranhão, escoando os grãos pela rodovia, passando pela ferrovia e chegando ao porto, porém, a região é propicia aos produtores que querem atingir o mercado consumidor externo, pois conta com todo o mecanismo para a exportação.

O quadro 1, a seguir, sintetiza os resultados. 


\begin{tabular}{|c|c|c|c|c|c|c|}
\hline Questionamentos & Produtor 1 & Produtor 2 & Produtor 3 & Produtor 4 & Produtor 5 & Produtor 6 \\
\hline Qual o critério da escolha do local? & Critério Técnico/manejo & $\begin{array}{l}\text { Critério técnico/ } \\
\text { manejo }\end{array}$ & $\begin{array}{l}\text { Critério técnico/ } \\
\text { manejo }\end{array}$ & $\begin{array}{l}\text { Critério técnico/ } \\
\text { manejo }\end{array}$ & $\begin{array}{l}\text { Critério técnico/ } \\
\text { manejo }\end{array}$ & $\begin{array}{l}\text { Critério técnico/ } \\
\text { manejo }\end{array}$ \\
\hline Como Funciona a logística do Local? & $\begin{array}{l}\text { Critério Técnico/ } \\
\text { Mercadológico }\end{array}$ & $\begin{array}{l}\text { Critério Técnico/ } \\
\text { Mercadológico }\end{array}$ & $\begin{array}{l}\text { Critério Técnico/ } \\
\text { Mercadológico }\end{array}$ & $\begin{array}{l}\text { Critério Técnico/ } \\
\text { Mercadológico }\end{array}$ & $\begin{array}{l}\text { Critério Técnico/ } \\
\text { Mercadológico }\end{array}$ & $\begin{array}{l}\text { Critério Técnico/ } \\
\text { Mercadológico }\end{array}$ \\
\hline Vantagens e Desvantagens do Local & $\begin{array}{l}\text { Critério Técnico } \\
\text { Mercadológico; falta de } \\
\text { infra-estrutura. }\end{array}$ & $\begin{array}{c}\text { Critério Técnico } \\
\text { Manejo; falta de infra- } \\
\text { estrutura. }\end{array}$ & $\begin{array}{l}\text { Critério Técnico } \\
\text { Mercadológico; } \\
\text { falta de } \\
\text { infraestrutura. }\end{array}$ & $\begin{array}{l}\text { Critério Técnico } \\
\text { Manejo; falta de } \\
\text { infraestrutura. }\end{array}$ & $\begin{array}{l}\text { Critério Técnico } \\
\text { Manejo; falta de } \\
\text { infraestrutura. }\end{array}$ & $\begin{array}{l}\text { Critério Técnico } \\
\text { Manejo; falta de } \\
\text { infraestrutura. }\end{array}$ \\
\hline Qual o critério de conhecimento do local? & $\begin{array}{l}\text { Através de uma } \\
\text { cooperativa }\end{array}$ & $\begin{array}{l}\text { Através de uma } \\
\text { cooperativa }\end{array}$ & $\begin{array}{l}\text { Através de uma } \\
\text { cooperativa }\end{array}$ & $\begin{array}{l}\text { Através de uma } \\
\text { cooperativa }\end{array}$ & $\begin{array}{l}\text { Através de uma } \\
\text { cooperativa }\end{array}$ & $\begin{array}{l}\text { Através de uma } \\
\text { cooperativa }\end{array}$ \\
\hline $\begin{array}{l}\text { Fez um planejamento sobre plantar na } \\
\text { região? }\end{array}$ & $\begin{array}{l}\text { Sim por entidades como } \\
\text { Embrapa e Cooperativas }\end{array}$ & $\begin{array}{l}\text { Sim por uma empresa } \\
\text { de consultoria do local }\end{array}$ & $\begin{array}{l}\text { Sim, por conta } \\
\text { própria. }\end{array}$ & $\begin{array}{l}\text { Sim, através de } \\
\text { empresa de } \\
\text { consultoria. }\end{array}$ & $\begin{array}{l}\text { Sim com um } \\
\text { consultor da área }\end{array}$ & $\begin{array}{l}\text { Sim, por uma } \\
\text { empresa de } \\
\text { consultoria. }\end{array}$ \\
\hline $\begin{array}{l}\text { Benefícios da região em relação à } \\
\text { Ituverava }\end{array}$ & Preço por Ha & Nenhum & Nenhum & Preço por ha & $\begin{array}{l}\text { Topografia, e } \\
\text { logística de } \\
\text { escoamento. }\end{array}$ & Preço por ha \\
\hline Existem cooperativas no local & Não & Não & Não & Não & Não & Não \\
\hline Existe incentivo na região para exportação & Não & Não & Não & Não & Não & Não \\
\hline $\begin{array}{l}\text { O transporte lá é mais viável do que na sua } \\
\text { região? }\end{array}$ & Sim por critério logístico & $\begin{array}{c}\text { Não por causa da falta } \\
\text { de infraestrutura das } \\
\text { rodovias }\end{array}$ & $\begin{array}{l}\text { Sim por critério } \\
\text { Logístico }\end{array}$ & $\begin{array}{l}\text { Sim por critério } \\
\text { Logístico }\end{array}$ & $\begin{array}{l}\text { Sim por critério } \\
\text { Logístico }\end{array}$ & $\begin{array}{l}\text { Sim por critério } \\
\text { Logístico }\end{array}$ \\
\hline A produção é maior do que no Sudeste & $\begin{array}{l}\text { Sim, Critério Técnico de } \\
\text { Manejo. }\end{array}$ & $\begin{array}{l}\text { Sim, Critério Técnico/ } \\
\text { Manejo. }\end{array}$ & $\begin{array}{l}\text { Sim Critério } \\
\text { técnico/Manejo }\end{array}$ & $\begin{array}{c}\text { Sim, Critério } \\
\text { Técnico/ Manejo. }\end{array}$ & $\begin{array}{c}\text { Sim, Critério } \\
\text { Técnico/ Manejo. }\end{array}$ & $\begin{array}{c}\text { Sim, Critério } \\
\text { Técnico/ Manejo. }\end{array}$ \\
\hline A logística é mais eficiente? & $\begin{array}{l}\text { Sim, deixando a desejar na } \\
\text { infraestrutura. }\end{array}$ & $\begin{array}{c}\text { Sim, deixando a } \\
\text { desejar na } \\
\text { infraestrutura. }\end{array}$ & $\begin{array}{l}\text { Sim, critério } \\
\text { técnico logístico }\end{array}$ & $\begin{array}{l}\text { Falta infra- } \\
\text { estrutura }\end{array}$ & $\begin{array}{c}\text { Sim, deixando a } \\
\text { desejar na } \\
\text { infraestrutura. }\end{array}$ & $\begin{array}{c}\text { Sim, deixando a } \\
\text { desejar na } \\
\text { infraestrutura. }\end{array}$ \\
\hline Existem oportunidades para exportação & $\begin{array}{l}\text { Sim, Critério/ } \\
\text { técnico Mercadológico. }\end{array}$ & $\begin{array}{l}\text { Sim, Critério/ } \\
\text { técnico Mercadológico. }\end{array}$ & $\begin{array}{c}\text { Sim, } \\
\text { Critério/técnico } \\
\text { Mercadológico. }\end{array}$ & $\begin{array}{l}\text { Sim, Critério/ } \\
\text { técnico } \\
\text { Mercadológico. }\end{array}$ & $\begin{array}{l}\text { Sim, Critério/ } \\
\text { técnico } \\
\text { Mercadológico. }\end{array}$ & $\begin{array}{l}\text { Sim, Critério/ } \\
\text { técnico } \\
\text { Mercadológico. }\end{array}$ \\
\hline
\end{tabular}

Quadro 1: síntese das respostas dos produtores. 


\section{CONSIDERAÇÕES FINAIS}

O objetivo do presente estudo foi de demonstrar a viabilidade na logística de transportes, com o Corredor de Exportação Norte, que abrange os estados do Sudeste do Piauí, Sul do Maranhão e Norte e Sudeste do Tocantins.

Em síntese, temos o seguinte para decisão de plantio no sul do Maranhão: primeiro pelo critério de logística de escoamento de grãos, uns dos melhores do Brasil, com a facilidade no transporte de grãos através do sistema rodoviário, ferroviário e marítimo; segundo pela topografia da região e tipo de solo, propício ao desenvolvimento agrário e terceiro pelo baixo custo na aquisição de terra de cerrados, onde já foram implantados vários projetos agrícolas, com a vegetação do cerrado brasileiro, facilitando o desmatamento e ainda não encontrando maiores resistências quanto aos ambientalistas com relação aos outros tipos de vegetação nativa.

O sul do Maranhão, Piauí e oeste da Bahia são regiões semelhantes que tiveram um desenvolvimento vertical nestes últimos dez anos, graças aos critérios existente acima e, principalmente, pela força do mercado internacional ascendente pelas commoties agrícolas.

O gerenciamento de custos relacionados à logística em ambientes competitivos se apresenta tão necessário quanto o próprio custo de produção, podendo-se dizer que são custos que fazem parte da cadeia produtiva.

Destaca-se que existe uma transformação conceitual do processo logístico, uma vez que o preço de compra passa a ser visto apenas como um dos custos de aquisição, ou seja, também se considera os custos de colocação do pedido, transporte, recebimento e estoque de materiais.

Assim, para o cálculo do custo total de um produto deve-se considerar a soma de todos os custos desse processo, desde a compra até a estocagem. Por fim, ressalta-se também que em determinadas empresas, os custos de logística terão maior impacto no custo total do produto que em outras, pois dependerá de determinadas especificidades do produto, especialmente relativas a características físicas, como tamanho e fragilidade, além de especificidades da própria empresa, como a localização geográfica, fato que mostra como a logística pode produzir impactos no projeto de instalação da empresa na fase de planejamento. 


\section{REFERÊNCIAS}

BALLOU, H. R. Logística Empresarial. São Paulo: Atlas, 1996.

BERnARDO, M. S. MUSSETTI, M. A. Custo Logístico versus Nível de Serviços. Disponível em: < www.lticonsultoria.com.br>. Acesso em 08.ago. 2007.

CORONADO, O. Controladoria no atacado e varejo: logística integrada e modelo de gestão sob a óptica da gestão econômica logisticon. São Paulo: Atlas, 2001.

DIAS, Marco Aurélio P. Administração de Materiais: uma abordagem logística. $4^{\circ}$ Ed. São Paulo. Atlas, 1993.

MAHER, M. Contabilidade de Custos: criando valor para a administração. São Paulo: Atlas, 2001.

MARTINS, G.de A. Estudo de Caso: uma Estratégia de Pesquisa. $1^{\text {a }}$ ed. SP: Atlas, 2006.

PAGOTTO, L.de S.; PIROLA, E. B; SILVA, J. Logística, uma ferramenta estratégica para gerenciamento na cadeia de suprimentos e para redução de custos. In XVI Congresso Brasileiro de Contabilidade, CD-ROM, 2000.

WOOD JR., T. ZUFFO, P. K. Supply chain management: uma abordagem estratégica para a logística. Anais do $21^{\circ}$ ENANPAD. Rio das Pedras, Brasil, 1997.

YIN, R. K. Estudo de caso: planejamento e método. 3. ed. Porto Alegre: Bookman, 2005. 